\title{
Myocardial Perfusion and Performance after Indomethacin Administration in Newborn Lambs
}

\author{
R. J. M. KLAUTZ, F. VAN BEL, D. F. TEITEL, P. STEENDIJK, AND J. BAAN \\ Clinical Physiology Laboratory, Departments of Pediatrics and Cardiology, Leiden University Hospital, Leiden,
} The Netherlands

\begin{abstract}
Indomethacin is a drug widely used to achieve pharmacologic closure of a patent ductus arteriosus in the premature infant. In several vascular beds (brain, kidney, intestine), indomethacin has been shown to cause vasoconstriction. Possible negative effects on myocardial blood flow and performance could be deleterious in premature infants with limited cardiac reserve. Before, during, and 30 and $60 \mathrm{~min}$ after administration of $1 \mathrm{mg} \cdot \mathrm{kg}^{-1}$ of indomethacin in nine newborn lambs, we measured coronary blood flow velocity (Doppler flow probe around the left circumflex coronary artery), left ventricular (LV) pressure (by tip manometer) and volume (by conductance catheter technique), cardiac output, arterial pressure, arterial and venous saturations and calculated systemic and coronary vascular resistance, LV systolic function by the endsystolic pressure-volume relationship, and myocardial oxygen extraction. To investigate the effect of indomethacin on the flow regulation of the coronary vascular bed, we measured coronary flow and $\mathrm{LV}$ function under different levels of myocardial demand, achieved by stepwise occluding of the descending aorta. During indomethacin infusion, coronary and systemic vascular resistance increased significantly (by 43 and $76 \%$, respectively), resulting in an increase in arterial pressure from 10.2 to $16.9 \mathrm{kPa}$, whereas neither coronary flow nor LV systolic function changed despite the increase in afterload. Thirty and $60 \mathrm{~min}$ after indomethacin, coronary and systemic vascular resistance had returned to baseline levels and $L V$ systolic function remained unchanged. The relationship between coronary flow and cardiac demand was not different before or after indomethacin. These results suggest that indomethacin may transiently impair the ability of the newborn heart to respond to increased myocardial demand by causing coronary vasoconstriction but does not impair myocardial performance, either at baseline or in response to increasing demand. (Pediatr Res 33: 295-301, 1993)
\end{abstract}

\section{Abbreviations}

CO, cardiac output

$\mathrm{E}_{\text {es }}$, end systolic elastance

ESPVR, end-systolic pressure-volume relationship

HR, heart rate

IVC, inferior vena cava

$L V$, left ventricle

MFVcor, mean coronary flow velocity

Pao, aortic pressure

Received January 31, 1992; accepted October 8, 1992

Correspondence: Robert J. M. Klautz, M.D. c/o D. F. Teitel, M.D., Cardiovascular Research Institute, University of California, San Francisco, Box 0544, San Francisco, CA 94143.

Reprint requests: F, van Bel, MD., Department of Pediatrics, Neonatal Unit, University Hospital Leiden, P.O. Box 9600, 2300 RC Leiden, The Netherlands

Supported by a grant from the Ghisela Thier Foundation, Leiden, The Netherlands (R.J.M.K.).
Rsyst, systemic vascular resistance

Rcor, coronary vascular resistance

$\mathbf{R}_{\mathbf{i}}$ cor, coronary vascular resistance index

SV, stroke volume

SW, stroke work

$V_{14}$, volume intercept at $L V$ pressure of $14 \mathrm{kPa}$

$V_{0}$, volume intercept at $L V$ pressure of $0 \mathrm{kPa}$

$\mathrm{dP} / \mathrm{dt}_{\max }$, maximum change in pressure per unit time

The cyclooxygenase inhibitor indomethacin is frequently used for noninvasive closure of symptomatic patent ductus arteriosus in preterm infants. Indomethacin has also been used increasingly for treatment of preterm labor. Experimental and clinical studies have shown a vasoconstrictive action of indomethacin on the vascular bed of important organ systems like the brain, kidneys, and intestines $(1-3)$. Some investigators also found indications that i.v. and oral treatment with indomethacin has negative effects on coronary flow and ventricular performance in humans: using the thermodilution technique, coronary vasoconstriction was found despite an increase in myocardial oxygen demand in adult patients with coronary artery disease (4-6). Moreover, Appleton et al. (6), who analyzed LV function after indomethacin administration in the newborn baby using M-mode echocardiography, reported that myocardial function during the diastolic phase was affected, whereas systolic function was not changed. Systolic function in the study of Appleton et al. was determined by the use of single-beat preejection-or ejection-phase indices of performance, which may not reliably assess myocardial performance, especially when afterload is changing.

Although there are indications that indomethacin has significant cardiovascular effects in neonates, its effect on coronary blood flow and systolic ventricular function has not yet been well defined. The potential negative effects of indomethacin are particularly important in the preterm infant with a patent ductus arteriosus, in whom cardiac function is compromised and coronary oxygen reserve may be limited. We therefore designed the present study to investigate the influence of indomethacin on general hemodynamics, myocardial blood flow, systolic ventricular function, and myocardial energetics.

\section{MATERIALS AND METHODS}

Surgical and experimental procedures used were reviewed and approved by the animal research committee of the Leiden University Hospital. Nine newborn lambs, weighing 3.4 to $5.5 \mathrm{~kg}$ (mean $4.5 \pm 0.7 \mathrm{~kg}$ ), were studied between 3 and $14 \mathrm{~d}$ of age (mean $8.8 \pm 3.7 \mathrm{~d}$ ).

Surgical protocol. After premedication with ketamine hydrochloride ( $3 \mathrm{mg} \cdot \mathrm{kg}^{-1}$ i.v.), general anesthesia was maintained using a continuous infusion of ketamine hydrochloride $(8-30$ 295 
an oxygen/air mixture using a pressure-regulated ventilator. Ventilation was adjusted to maintain arterial $\mathrm{PO}_{2}$ and $\mathrm{PCO}_{2}$ in the normal range throughout the study. Pancuronium $\left(0.2 \mathrm{mg} \cdot \mathrm{kg}^{-1}\right)$ was administered as needed to maintain adequate muscle relaxation. An i.v. infusion of $10 \%$ dextrose in $0.5 \mathrm{~N} \mathrm{NaCl}$ solution was continued throughout the study at about $10 \mathrm{~mL} \cdot \mathrm{kg}^{-1} \cdot \mathrm{h}^{-1}$, occasionally supplemented with $\mathrm{NaHCO}_{3}$ as needed to maintain a normal base deficit $\left(\leq 5 \mathrm{mmol} \cdot \mathrm{L}^{-1}\right)$.

In both right and left femoral arteries and veins, $6 \mathrm{~F}$ or $7 \mathrm{~F}$ sheaths were placed using a percutaneous technique. On one side, $5 \mathrm{~F}$ atrioseptostomy catheters (American Edwards Laboratories, Irvine, CA) were advanced in the artery and vein to the mid-thoracic aorta and the IVC-right atrial junction for increasing afterload and decreasing preload, respectively. In one femoral artery, a $6 \mathrm{~F}$, eight-pole (5.5-mm interelectrode distance) pigtail conductance catheter (Webster Laboratories, Baldwin Park, CA) was advanced to the apex of the LV. The catheter was connected to a Leycom Sigma-5 signal-conditioner-processor (CardioDynamics, Rijnsburg, The Netherlands), to convert instantaneous conductance measurements to ventricular volume. A $5 \mathrm{~F}$ Berman angiographic catheter (American Edwards Laboratories) was advanced through the other femoral vein to the main pulmonary artery for the determination of parallel conductance volume with the hypertonic salt injection method, to obtain volume in absolute sense (7). Via a small incision in the neck, one carotid artery was dissected, a $6 \mathrm{~F}$ sheath was introduced, and through it a $5 \mathrm{~F}$ micro-tip manometer catheter (Dräger Medical Electronics, Best, The Netherlands) was advanced into the left ventricle just below the aortic valve. Pao was measured from the fluid-filled sideport of the sheath in the neck using a pressure transducer. The sideport of any arterial sheath was used to draw blood samples for measurement of arterial blood gases and $\mathrm{Hb}$ concentration.

After confirmation using fluoroscopy, of adequate catheter positions, the thorax was opened on the left side in the 4th intercostal space. In four animals, the azygos vein was ligated distally, and a $4 \mathrm{~F}$ multipurpose catheter was advanced proximally into the coronary sinus for coronary venous blood samples of Hb oxygen saturation and lactate concentration. After opening the pericardium, the left circumflex artery, which in all lambs appeared to be the largest coronary artery and, consequently, probably supplies the largest part of the $\mathrm{LV}$, was carefully dissected and a 2.0 - or $2.5-\mathrm{mm}$ perivascular Doppler flow (velocity) probe was fitted around this vessel. The probe was connected to a $20-\mathrm{MHz}$ range-gated pulsed Doppler flow meter (Crystal Biotech, Holliston, MA), which was adjusted to detect the highest possible velocity for subsequent determination of the optimum blood flow velocity wave form in a calibrated fashion.

All analog signals were displayed on a paper recorder and screen for continuous monitoring. The LV pressure and total LV volume signals were also displayed on a X-Y oscilloscope for continuous monitoring of pressure-volume loops. All analog signals were digitized with 12-bit accuracy on an IBM compatible microcomputer (Epson AT), at a sampling rate of $200 \mathrm{~Hz}$, and saved on a hard disk for subsequent analysis.

Study protocol. After completion of the surgical preparation, a 30 -min period was instituted to achieve hemodynamic stability. During the study, the animals were kept under parasympathetic blockade with atropine $\left(0.1 \mathrm{mg} \cdot \mathrm{kg}^{-1}\right.$ i.v. as necessary) to prevent changes in HR when Pao changed. We acquired four sets of information under a variety of experimental conditions. The first set was general hemodynamics, which consisted of Pao, SW, SV, $\mathrm{HR}, \mathrm{CO}$, and Rsyst (see below for calculations). The second set was coronary flow and Rcor. Changes in coronary flow caused by a vasoconstrictive drug such as indomethacin can be due either to direct effects on the coronary vessels or to metabolic regulation; to adapt the oxygen supply of the heart to the increased demand imposed on the heart by increasing Pao, the coronary flow will go up. To relate changes in coronary flow to changes in myocardial demand, steady-state measurements of coronary flow alone were inadequate. Thus, we varied central impedance by stepwise inflation of the aortic balloon catheter. We performed measurements at three to five different levels of this afterload and constructed a SW versus coronary flow relationship.

The third set of information consisted of measuring systolic ventricular performance using two indices of contractility: the ESPVR and the $\mathrm{dP} / \mathrm{dt}_{\max }$ corrected for end diastolic volume. The application, validation, and calibration of the conductance catheter for measuring LV volume and its use to measure the ESPVR as an index of systolic performance has been described extensively in adult dog hearts (7-10), human hearts (7), and recently in small (lamb and pig) hearts $(11,12)$. Briefly, LV pressure and volume are recorded during gradual inflation of the IVC balloon to restrict venous return and decrease the preload of the heart. During this unloading intervention, a line (ESPVR) is constructed through the end-systolic pressure-volume points (upper left-hand corners of the pressure-volume loops). The slope of the line $\left(E_{c s}\right)$ and its position (usually at a fixed pressure of $14 \mathrm{kPa}$ $=\mathrm{V}_{14}$ ) represent an index of intrinsic contractility; both an increase in slope and a leftward shift of the line have been shown to represent increased contractile state $(13,14)$. These measurements were performed at end-expiration with the ventilator turned off. Instantaneous LV pressure and volume were measured simultaneously using the micro-tip manometer and conductance catheter, respectively, and pressure-volume loops were constructed for each beat. It is clear that the ESPVR can only be calculated during a loading intervention while nothing else is changing. During the acute situation, however, immediately after the administration of indomethacin, there was no steady-state period. We therefore used another index in this situation, the $\mathrm{dP} / \mathrm{dt}_{\max }$ corrected for end diastolic volume, which can be calculated in a beat-to-beat fashion. This index is a well established index of contractility (15) and easily calculated from the first derivative of the pressure signal. Values are compared by either matching for end diastolic volume or by calculating a slope of the $\mathrm{dP} / \mathrm{dt}_{\max }-$ end-diastolic volume relationship and comparing the slopes. In this study, we used the first method.

The fourth set of information consisted of measurements of coronary arterial and venous oxygen saturation and Hb concentration and coronary venous lactate concentration. Myocardial oxygen extraction was calculated using these values.

We studied the following conditions: first, control conditions before indomethacin infusion, when hemodynamic variables, baseline coronary flow, ventricular performance, and metabolic data were measured. Hemodynamic variables and coronary flow were also measured at different levels of afterload, and the control SW versus coronary flow relationship was constructed. Subsequently, hemodynamic parameters and baseline coronary flow were recorded 1 ) immediately before indomethacin infusion to obtain a second control condition, 2) during the infusion itself until 1 min after the infusion had stopped, 3) subsequently for $10 \mathrm{~s}$ every $5 \mathrm{~min}$ during the next $30 \mathrm{~min}$, and 4) at 30 and 5) at $60 \mathrm{~min}$ after indomethacin was slowly given i.v. in $60 \mathrm{~s}$ in a dose of $1.0 \mathrm{mg} \cdot \mathrm{kg}^{-1}$. Indomethacin was dissolved in distilled water and buffered with $\mathrm{NaHCO}_{3}(8.4 \%)$ to a pH value of 7.5 . Additionally, ventricular performance and blood biochemical measurements were recorded immediately before indomethacin infusion and 1 (no biochemical measurements at $1 \mathrm{~min}$ ), 30, and $60 \mathrm{~min}$ after indomethacin infusion. Between the measurements at 30 and $60 \mathrm{~min}$, coronary flow was measured again at different levels of SW. For descriptive purposes, the protocol is presented graphically in Figure 1.

Calculations. General hemodynamic measurements were analyzed from the first 10 steady-state beats of each run. Mean Pao, SW, SV, HR, CO, and total Rsyst were either analyzed or calculated in a beat-to-beat fashion, using a special-application software program, Conduct-PC (CardioDynamics), which calculated SW [as the area enclosed by the pressure (P)-volume (V) loop, formula 1], SV (end-diastolic volume minus end-systolic 


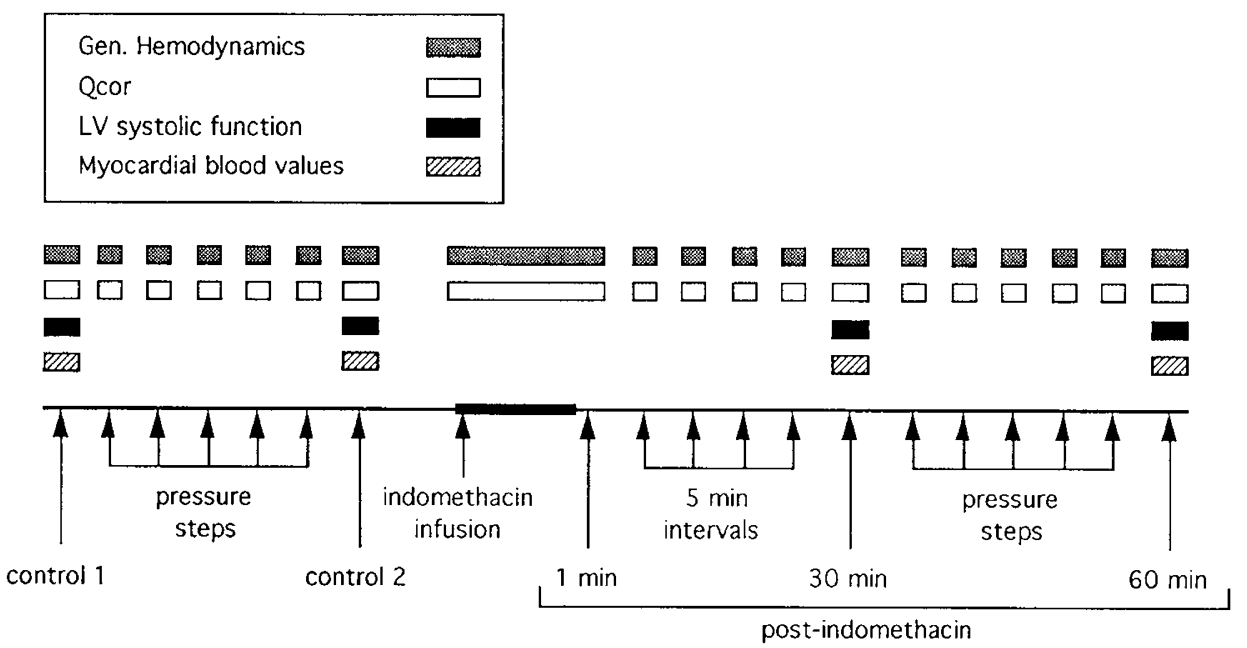

Fig. 1. Graphic representation of the study protocol. Pressure steps represent increases in aortic impedance to distinct levels by aortic occlusion; LV systolic function obtained by ESPVR (see text). Qcor, coronary flow velocity.

volume), and HR from the pressure and volume data. $\mathrm{CO}$ and Rsyst were calculated using formulas 2 and 3 . Finally, the data were averaged over the 10 beats.

$$
\begin{aligned}
& \mathrm{SW}=\int \mathrm{PdV} \\
& \mathrm{CO}=\mathrm{HR} \cdot \mathrm{SV} \\
& \text { Rsyst }=\frac{\mathrm{PaO}}{\mathrm{CO}}
\end{aligned}
$$

In the latter formula, the (small) influence of the low venous pressure has been neglected.

MFVcor and Rcor were analyzed from the same first 10 steady-state beats as the general hemodynamics. They were calculated in a beat-to-beat fashion and then averaged over the 10 beats. Coronary flow velocity was calculated from the frequency shift $\Delta \mathrm{f}$ in $\mathrm{kHz}$ to $\mathrm{cm} \cdot \mathrm{s}^{-1}$ using formula 4 , and Rcor was approximated in a qualitative fashion with the use of formula 5. To discern it from a real vascular resistance, we will refer to this variable as $\mathrm{R}_{\mathrm{i}}$ cor.

$$
\begin{aligned}
& \text { Flow velocity }\left(\mathrm{cm} \cdot \mathrm{s}^{-1}\right)=5.3 \cdot \Delta \mathrm{f}(\mathrm{kHz}) \\
& \mathrm{R}_{\mathrm{i}} \operatorname{cor}\left(\mathrm{kPa} \cdot \mathrm{cm}^{-1} \cdot \mathrm{s}\right)=\frac{\mathrm{Pao}(\mathrm{kPa})}{\mathrm{MFVcor}\left(\mathrm{cm} \cdot \mathrm{s}^{-1}\right)}
\end{aligned}
$$

Mean coronary flow velocity is related to SW by linearly regressing MFVcor versus SW.

Data analysis for the estimation of ventricular performance from the pressure and volume data by the ESPVR was performed using the Conduct-PC software program. The program determines the end-systolic points using an iterative approach. $\mathrm{E}_{\mathrm{es}}$ and the $\mathrm{V}_{0}$ are calculated from linearly regressing end-systolic pressure $\left(\mathrm{P}_{\mathrm{es}}\right)$-volume $\left(\mathrm{V}_{\mathrm{es}}\right)$ points (formula 6$)$, beginning with an assumed $\mathrm{V}_{0}$ of $0 \mathrm{~mL}$ and continuing until the iteration results in a change in $V_{0}$ of $\leq 0.1 \mathrm{~mL}$ from the previous iteration; $V_{14}$ is then determined as the end-systolic volume intercept of the ESPVR at $14 \mathrm{kPa}$ (formula 7). We preferred the use of $V_{14}$ to characterize the position of the ESPVR over the use of $V_{0}$ because the former value occurs within the range of measurement values, whereas $V_{0}$ only follows from linear extrapolation of data points to a point far outside this range.

$$
\begin{gathered}
P_{e s}=E_{e s} \cdot\left(V_{e s}-V_{0}\right) \\
V_{14}=\frac{14}{E_{e s}}+V_{0}
\end{gathered}
$$

The same software program calculated $\mathrm{dP} / \mathrm{dt}_{\max }$ for each beat, and this value was matched with end-diastolic volume by manual comparison to the values at the same time.

Myocardial oxygen extraction (Ox Extr) was calculated as:

Ox Extr $\left[\mathrm{mL} \mathrm{O}_{2}(\mathrm{~mL} \text { blood })^{-1}\right]$

$$
=[\mathrm{A}-\mathrm{V} \text { sat. dif. }(\%)] \cdot[\mathrm{Hb}(\mathrm{g} / 100 \mathrm{~mL})] \cdot 0.136
$$

where A-V sat. dif. is the coronary arteriovenous oxygen saturation difference.

Statistical analysis. The two control conditions were compared with each other using a paired $t$ test. Data from all animals in the four experimental conditions (first control, $1 \mathrm{~min}, 30 \mathrm{~min}$, and 60 min after indomethacin) were compared with each other using a two-way analysis of variance for repeated measures. The conditions after indomethacin administration were compared with the control condition using Scheffe's (multiple contrasts) $F$ test. Significance level was set at $95 \%$. Whenever there were missing values, the mean for that parameter for all the animals was used. To test whether the relation between coronary flow velocity and SW (during the increasing afterload steps) was influenced by indomethacin, a multiple linear regression model with dummy variables was used. The regression equation was:

$$
\mathrm{Y}=\mathrm{a}_{0}+\mathrm{a}_{\mathrm{x}} \mathrm{X}+\mathrm{a}_{\mathrm{i}} \mathrm{I}+\mathrm{a}_{\mathrm{xi}} \mathrm{X} \cdot \mathrm{I}+\sum_{k=1}^{8} \mathrm{a}_{\mathrm{l}_{\mathrm{k}}} \mathrm{L}_{\mathrm{k}}
$$

where $\mathrm{Y}$ is the dependent variable (coronary flow), and $\mathrm{a}_{0}$ is its mean value over all the runs. $X$ is the first independent variable $(\mathrm{SW}) . \mathrm{I}$ is the drug variable, representing the conditions with (value +1 ) or without indomethacin (value of -1 ), which allows the relation between $\mathrm{Y}$ and $\mathrm{X}$ to shift in a parallel fashion. The interaction variable $X$.I represents the effect of indomethacin on the relationship between coronary flow velocity and SW. To assess the interanimal variability, eight lamb variables $\mathrm{L}_{1}$ to $\mathrm{L}_{8}$ were introduced. The interanimal variables were coded by effects (16).

\section{RESULTS}

No difference in any variable measured between control condition 1 and control condition 2 (approximately 30 min later) could be revealed by paired $t$ test (Table 1). Therefore, only comparisons of the other study conditions to control condition 1 were made.

General hemodynamic parameters. Table 2 lists the most important hemodynamic variables as well as the accessory statistics for these parameters. In the 1st min after indomethacin, mean Pao increased from $10.2 \pm 2.4$ to $16.9 \pm 3.5 \mathrm{kPa}(66 \%$ 
Table 1. Pao, SW, SV, HR, CO, Rsyst, MFVcor, $R_{i}$ cor, $E_{e s}$, and $V_{14}$ during control conditions 1 and 2 and the $p$ value of the paired t test

\begin{tabular}{lccc}
\hline & $\begin{array}{c}\text { Control 1 } \\
\text { mean } \pm \text { SD }\end{array}$ & $\begin{array}{c}\text { Control 2 } \\
\text { mean } \pm \mathrm{SD}\end{array}$ & $p$ \\
\hline $\mathrm{Pao}(\mathrm{kPa})$ & $10.2 \pm 2.4$ & $11.2 \pm 2.4$ & 0.532 \\
$\mathrm{SW}\left(\mathrm{J} \cdot \mathrm{min}^{-1}\right)$ & $5.2 \pm 2.8$ & $5.5 \pm 3.7$ & 0.801 \\
$\mathrm{SV}(\mathrm{mL})$ & $2.9 \pm 1.5$ & $2.7 \pm 1.3$ & 0.249 \\
$\mathrm{HR}\left(\mathrm{beats} \cdot \mathrm{min}^{-1}\right)$ & $192 \pm 35$ & $209 \pm 35$ & 0.138 \\
$\mathrm{CO}\left(\mathrm{L} \cdot \mathrm{min}^{-1}\right)$ & $0.54 \pm 0.24$ & $0.56 \pm 0.30$ & 0.861 \\
$\mathrm{Rsyst}\left(\mathrm{kPa} \cdot \mathrm{L}^{-1} \cdot \mathrm{min}^{-1}\right)$ & $22.5 \pm 12.7$ & $27.3 \pm 19.6$ & 0.269 \\
$\mathrm{MFV} \mathrm{cor}\left(\mathrm{cm} \cdot \mathrm{s}^{-1}\right)$ & $9.1 \pm 4.7$ & $11.2 \pm 5.0$ & 0.344 \\
$\mathrm{R}_{\mathrm{i}} \mathrm{cor}\left(\mathrm{kPa} \cdot \mathrm{cm}^{-1} \cdot \mathrm{s}\right)$ & $1.4 \pm 0.8$ & $1.17 \pm 0.51$ & 0.662 \\
$\mathrm{E}_{\mathrm{cs}}\left(\mathrm{kPa} \cdot \mathrm{mL}^{-1}\right)$ & $6.7 \pm 6.6$ & $6.3 \pm 4.7$ & 0.541 \\
$\mathrm{~V}_{14}(\mathrm{~mL})$ & $3.1 \pm 1.6$ & $2.5 \pm 1.8$ & 0.416 \\
\hline
\end{tabular}

increase), and total peripheral resistance increased from $22.5 \pm$ 12.7 to $39.7 \pm 23.3 \mathrm{kPa} \cdot \mathrm{L}^{-1} \cdot \mathrm{min}^{-1}$ (76\% increase). CO remained unchanged $\left(0.54 \pm 0.24 \mathrm{~L} \cdot \mathrm{min}^{-1}\right.$ before and $0.54 \pm 0.25 \mathrm{~L}$. $\min ^{-1} 1$ min after indomethacin). SW increased from $5.2 \pm 2.8$ to $6.9 \pm 2.8 \mathrm{~J} / \mathrm{min}$ ( $33 \%$ increase). At $30 \mathrm{~min}$ after indomethacin, none of the measured hemodynamic parameters was statistically different from the control values. The same holds for the measurements at 60 min after indomethacin.

Coronary flow. Time-tracings of LV-pressure, LV-volume and coronary flow velocity are plotted in Figure 2. From these tracings, it is clear that despite large changes in LV-pressure and $\mathrm{LV}$-volume there is almost no (adaptational) change in coronary flow velocity. Numerical values of MFVcor and $\mathrm{R}_{\mathrm{i}}$ cor are presented in Table 2. MFVcor did not change $\left(9.1 \pm 4.7 \mathrm{~cm}^{-1} \cdot \mathrm{s}^{-1}\right.$ before and $9.7 \pm 4.2 \mathrm{~cm}^{-1} \cdot \mathrm{s}^{-1} 1 \mathrm{~min}$ after indomethacin), whereas $R_{\mathrm{i}}$ cor increased from $1.4 \pm 0.8$ to $2.0 \pm 0.8 \mathrm{kPa} \cdot\left(\mathrm{cm}^{-1}\right.$. s) ( $43 \%$ increase). To detect changes in the autoregulatory ability of the coronary vascular bed, we analyzed the MFVcor versus SW relations obtained by Pao steps before and after indomethacin. Each step performed with the aortic balloon inflation increased central impedance, Pao, and SW. We were able to construct highly significant SW versus MFVcor relations. In Table 3, the slopes, intercepts, regression coefficients, and number of data points are listed. From a multiple linear regression analysis (Table 4), it is clear that all variance in the data is due to interanimal variability and not to the effect of indomethacin. In other words, the relationship between MFVcor and SW is the same before and after indomethacin.

Myocardial performance. In Figure 3, a typical set of pressurevolume loops during an IVC occlusion is presented. $\mathrm{E}_{\mathrm{es}}$ and $\mathrm{V}_{14}$ of each animal are listed in Table 2 together with the accessory statistical values, which reveal no significant change in these values at 30 and 60 min after indomethacin, compared with control values. To assess the contractile effects during indomethacin administration, we measured $\mathrm{dP} / \mathrm{dt}_{\max }$ at matched preload. This value was not statistically different from control at $1 \mathrm{~min}$ after indomethacin administration, nor at 30 and $60 \mathrm{~min}$ (Table 2).

Myocardial oxygen extraction. Myocardial oxygen extraction, measured in four animals, did not change at $30 \mathrm{~min}(78.0 \pm 25.6$ $\mathrm{mL} \mathrm{O}_{2} / \mathrm{L}$ blood versus $78.0 \pm 18.7$ during control) or $60 \mathrm{~min}$ $\left(72.8 \pm 24.7 \mathrm{~mL} \mathrm{O}_{2} / \mathrm{L}\right.$ blood) after indomethacin (see Table 2). Lactate levels remained normal and similar in all conditions $\left(2.37 \pm 0.29 \mathrm{mmol} \cdot \mathrm{L}^{-1}\right.$ at control, $2.55 \pm 0.41 \mathrm{mmol} \cdot \mathrm{L}^{-1}$ at 30 $\mathrm{min}$, and $2.58 \pm 0.56 \mathrm{mmol} \cdot \mathrm{L}^{-1}$ at $60 \mathrm{~min}$ ).

\section{DISCUSSION}

We investigated the effects of a single dose of indomethacin on general hemodynamics, myocardial perfusion, and systolic performance, and found that a single dose had only brief, transient effects on both the general circulation and the coronary vascular bed. Total peripheral resistance and $\mathrm{R}_{\mathrm{i}}$ cor were markedly increased immediately after the infusion of the drug, whereas systemic flow and coronary flow velocity were not changed. These increases in resistance did not persist at 30 and $60 \mathrm{~min}$ after infusion. Myocardial performance did not change from control values at 1,30 , or 60 min after indomethacin administration.

To determine the effects of indomethacin on myocardial perfusion, we estimated left ventricular blood flow by obtaining Doppler-derived velocities from transducers directly applied to the left circumflex coronary artery. Measurements of coronary flow velocity with the Doppler flow technique carries some limitations because it measures velocity, and the calculated flow is dependent on the cross-sectional area of the vessel. Although the diameter of the left circumflex artery may change to some extent during changes in blood pressure, the resistance in the coronary vascular bed will largely be controlled by the arterioles situated distally to the left circumflex artery, which remains relatively unchanged (17). Furthermore, changes in the diameter of the vessel are unlikely, as we used slightly constricting perivascular probes that did not allow for changes in external vessel diameter. We therefore suggest that the changes in MFVcor reflect alterations in true coronary blood flow in the left circumflex artery. Another limitation of our instrumentation is that we were only able to measure coronary flow in one coronary vessel, but we were interested in total left ventricular myocardial blood flow. However, because we were primarily interested in changes

Table 2. Hemodynamic parameters and calculated myocardial performance and perfusion variables during control condition, 1 , 30, and 60 min after indomethacin administration (means $\pm S D$ ); results of one-factor analysis of variance for repeated measures; and results of Scheffe's $F$ test when control is compared with 1, 30, and 60 min after indomethacin administration*

\begin{tabular}{|c|c|c|c|c|c|c|c|c|c|}
\hline & \multicolumn{4}{|c|}{ Values } & \multicolumn{2}{|c|}{ ANOVA } & \multicolumn{3}{|c|}{ Scheffé's $F$ test } \\
\hline & Control & Indo $_{1}$ & $\mathrm{Indo}_{30}$ & Indo $_{60}$ & $F$ test & $p$ value & $\mathrm{C}-\mathrm{I}_{1}$ & $\mathrm{C}-\mathrm{I}_{30}$ & $\mathrm{C}-\mathrm{I}_{60}$ \\
\hline $\mathrm{Pao}(\mathrm{kPa})$ & $10.2 \pm 2.4$ & $16.9 \pm 3.5$ & $11.8 \pm 2.4$ & $12.0 \pm 2.4$ & 26.17 & 0.0001 & $22.23 \dagger$ & 1.25 & 0.68 \\
\hline $\mathrm{SW}\left(\mathrm{J} \cdot \mathrm{min}^{-1}\right)$ & $5.2 \pm 2.8$ & $6.9 \pm 2.8$ & $5.4 \pm 2.5$ & $5.0 \pm 2.7$ & 4.93 & 0.0083 & $3.79 \dagger$ & 0.03 & 0.07 \\
\hline $\mathrm{SV}(\mathrm{mL})$ & $2.9 \pm 1.4$ & $3.1 \pm 1.5$ & $2.4 \pm 1.2$ & $2.4 \pm 1.4$ & 7.67 & 0.0009 & 0.42 & $3.20 \dagger$ & 1.74 \\
\hline $\mathrm{HR}$ (beats $\cdot \mathrm{min}^{-1}$ ) & $192 \pm 35$ & $180 \pm 24$ & $217 \pm 33$ & $213 \pm 44$ & 5.66 & 0.0045 & 0.44 & 1.86 & 1.43 \\
\hline $\mathrm{CO}\left(\mathrm{L} \cdot \mathrm{min}^{-1}\right)$ & $0.54 \pm 0.24$ & $0.54 \pm 0.25$ & $0.52 \pm 0.24$ & $0.48 \pm 0.23$ & 0.12 & $>0.1$ & 0.001 & 0.07 & 0.02 \\
\hline Rsyst $\left(\mathrm{kPa} \cdot \mathrm{L}^{-1} \cdot \mathrm{min}^{-1}\right)$ & $22.5 \pm 12.7$ & $39.7 \pm 23.3$ & $32.5 \pm 29.6$ & $34.3 \pm 28.0$ & 4.91 & 0.0084 & $4.79 \dagger$ & 1.55 & 0.80 \\
\hline $\operatorname{MFV} \operatorname{cor}\left(\mathrm{cm} \cdot \mathrm{s}^{-1}\right)$ & $9.1 \pm 4.7$ & $9.7 \pm 4.2$ & $9.4 \pm 4.2$ & $10.5 \pm 3.0$ & 1.04 & $>0.1$ & 0.15 & 0.04 & 0.94 \\
\hline $\mathrm{R}_{\mathrm{i}} \operatorname{cor}\left(\mathrm{kPa} \cdot \mathrm{cm}^{-1} \cdot \mathrm{s}\right)$ & $1.4 \pm 0.8$ & $2.0 \pm 0.8$ & $1.5 \pm 0.6$ & $1.3 \pm 0.5$ & 9.00 & 0.0004 & $5.57 \dagger$ & 0.05 & 0.12 \\
\hline $\mathrm{E}_{\mathrm{cs}}\left(\mathrm{kPa} \cdot \mathrm{mL}^{-1}\right)$ & $6.7 \pm 6.6$ & NA & $9.5 \pm 8.2$ & $6.4 \pm 3.5$ & 2.17 & $>0.1$ & & 1.40 & 0.03 \\
\hline $\mathrm{V}_{14}(\mathrm{~mL})$ & $3.1 \pm 1.6$ & NA & $2.7 \pm 2.6$ & $3.1 \pm 4.6$ & 0.12 & $>0.1$ & & 0.12 & 0.06 \\
\hline $\mathrm{dP} / \mathrm{dt}_{\max }\left(\mathrm{kPa} \cdot \mathrm{s}^{-1}\right)$ & $599 \pm 84$ & $541 \pm 115$ & $517 \pm 91$ & $560 \pm 135$ & 1.67 & $>0.1$ & 0.68 & 0.13 & 0.45 \\
\hline $\mathrm{Ox} \operatorname{Extr}\left(\mathrm{mL} \mathrm{O}_{2} / \mathrm{mL}\right.$ blood $)$ & $78.0 \pm 18.7$ & $\mathrm{NA}$ & $78.0 \pm 25.6$ & $72.8 \pm 24.7$ & 0.92 & 0.43 & & 0.01 & 0.60 \\
\hline
\end{tabular}

* ANOVA, analysis of variance; Indo, indomethacin; C-I, control vs indomethacin; Ox Extr, oxygen extraction; NA, not available.

$\dagger$ Significant at $95 \%$. 

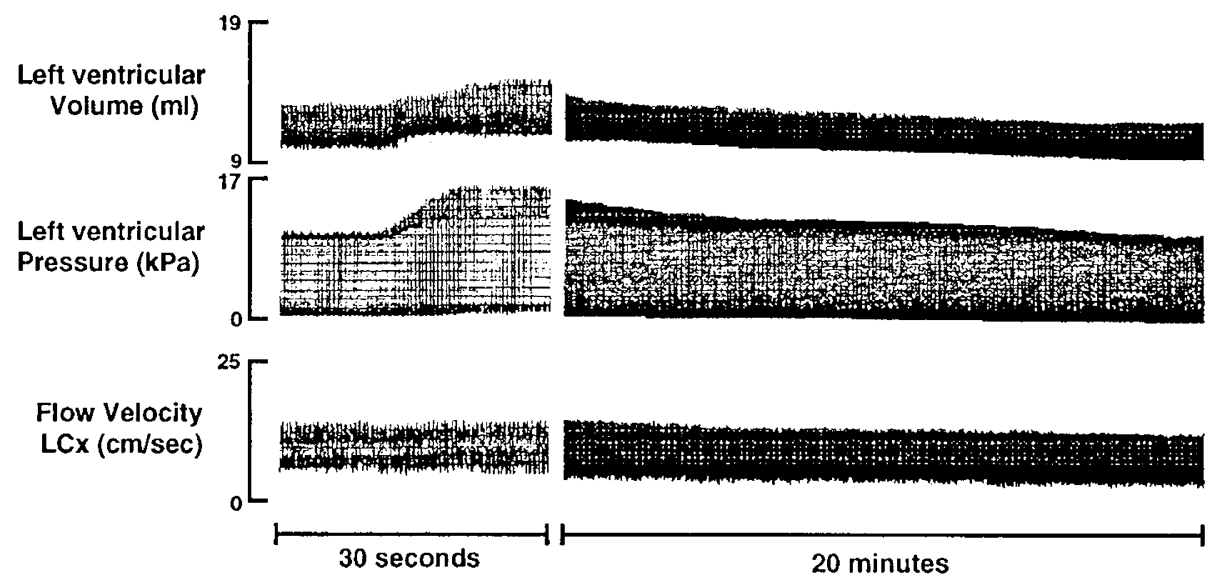

Fig. 2. LV pressure, LV volume, and coronary flow velocity tracing during indomethacin administration. $L C x$, left circumflex coronary artery.

Table 3. Overview of statistics (linear regression) of individual coronary flow velocity-SW relationships

\begin{tabular}{lllrrr}
\hline Animal & Condition & Slope & Intercept & $r$ & $n$ \\
\hline 01 & Cont* & 0.69 & 4.91 & 0.99 & 4 \\
02 & Indo & 0.76 & 1.94 & 0.99 & 6 \\
& Cont & 0.83 & -0.42 & 0.85 & 7 \\
03 & Indo & 4.44 & -31.10 & 0.99 & 3 \\
& Cont & 0.76 & -1.34 & 0.99 & 6 \\
04 & Indo & 0.52 & 1.11 & 0.99 & 5 \\
& Cont & 1.71 & 2.43 & 0.98 & 6 \\
05 & Indo & 1.21 & 3.89 & 0.97 & 6 \\
& Cont & 0.83 & 6.02 & 0.92 & 5 \\
06 & Indo & 1.44 & 4.26 & 0.80 & 6 \\
& Cont & 1.55 & 7.20 & 0.79 & 7 \\
07 & Indo & 1.60 & 9.25 & 0.79 & 6 \\
& Cont & 3.88 & -0.26 & 0.99 & 8 \\
08 & Indo & 4.15 & 0.41 & 0.95 & 7 \\
& Cont & 1.59 & 8.34 & 0.86 & 8 \\
09 & Indo & 1.66 & 10.00 & 0.61 & 8 \\
& Cont & 1.76 & -1.99 & 0.97 & 6 \\
& Indo & 2.28 & -5.05 & 0.98 & 6 \\
\multirow{2}{*}{ Mean \pm SD } & Cont & $1.42 \pm 0.88$ & $2.93 \pm 3.56$ & & \\
& Indo & $1.87 \pm 1.31$ & $-0.19 \pm 11.08$ & & \\
\hline
\end{tabular}

* Cont, control; Indo, postindomethacin.

in coronary flow and we assume a homogeneous distribution of blood flow, measurements in one vessel, which supplies at least $50 \%$ of the left ventricular myocardium, adequately reflect changes in total left ventricular myocardial blood flow. For the same reason, we did not attempt to calibrate the instrument for actual flow. Coronary flow measurements in small animals such as newborn lambs have been done with the use of microspheres by many groups. In our study, in which we needed frequent and continuous measurements of coronary blood flow in each animal, we could not use that method because we needed a more direct method. Based on our experience with Doppler flow probes, we were able to achieve continuous measurement of coronary flow (velocity). In this way, we were able to construct pressure- or SW-flow relationships of the coronary vascular bed.

Vane (18) showed in 1971 that indomethacin inhibits the enzyme cyclooxygenase, which converts arachidonic acid into unstable precursors of the prostaglandins, prostacyclins, and thromboxane. Prostaglandin is a potent vasodilator and plays an important role in keeping the ductus arteriosus open in the fetal circulation. Indomethacin, though, not only has strong vasoconstrictive effects on ductal tissue, but also exerts acute vasoconstrictive effects on other vascular beds. This was confirmed in our findings: total peripheral resistance increased, accompanied by an increase in arterial pressure and no change in $\mathrm{CO}$. These effects lasted for only a few minutes, because $30 \mathrm{~min}$ after indomethacin administration total peripheral resistance and arterial pressure had returned to preindomethacin levels. These general hemodynamic effects of indomethacin have been the reason many neonatal centers give indomethacin at a low infusion rate, as it appears to minimize the acute effects on arterial pressure.

The effects of indomethacin on the coronary circulation parallel those on the systemic circulation: Rcor increases, whereas flow remains unchanged. Vascular effects on coronary flow might be due either to the blockade of prostaglandin synthesis or to direct constrictive effects of the drug itself. The role of the prostaglandins as important modulators of coronary blood flow has been emphasized by Afonso et al. (19) and Needleman (20). More recent studies $(21,22)$, however, did not support the hypothesis that prostaglandins play a major role in coronary flow regulation. In these studies, coronary flow was studied during changes in cardiac demand by pacing. In our study, we increased the afterload of the ventricle during control measurements to match the increase in afterload with indomethacin. In this way, we were able to compare changes in coronary flow due to metabolic autoregulation (resulting from increased myocardial

Table 4. Multiple linear regression model for mean flow velocity of coronary artery $\left(\mathrm{cm} \cdot \mathrm{s}^{-1}\right)^{*}$

\begin{tabular}{|c|c|c|c|c|c|c|c|c|c|c|c|c|}
\hline \multirow[b]{2}{*}{ Variable } & \multirow[b]{2}{*}{$a_{0}$} & \multirow[b]{2}{*}{ SW } & \multirow{2}{*}{$\begin{array}{c}\text { Drug } \\
\text { variable: } \\
\text { Indo }\end{array}$} & \multirow{2}{*}{$\begin{array}{c}\text { Interaction } \\
\text { variable: } \\
\text { SW*I }\end{array}$} & \multicolumn{8}{|c|}{ Interanimal variability } \\
\hline & & & & & Ll & $\mathrm{L} 2$ & L3 & L4 & L5 & L6 & L7 & L8 \\
\hline $\mathrm{a}$ & 3.05 & 1.23 & -0.44 & 0.04 & -5.58 & -6.42 & -7.11 & 1.62 & 1.71 & 6.90 & 3.16 & 7.85 \\
\hline SEM & & 0.11 & 0.36 & 0.05 & 1.99 & 0.55 & 0.43 & 0.45 & 0.45 & 0.42 & 0.59 & 0.42 \\
\hline$p$ & & $<0.001$ & 0.22 & 0.44 & \multicolumn{8}{|c|}{ Coefficients combined: $<0.001$} \\
\hline
\end{tabular}

* The regression equation was statistically significant $(F$ test $=83.41, p<0.0001)$. The coefficients a are in $\mathrm{cm} \cdot \mathrm{s}^{-1}$. $\mathrm{a}_{0}=\mathrm{the}$ intercept of the equation, or overall mean flow velocity (MFV). Independent variables: $\mathrm{SW}$ in $\mathrm{J} \cdot \mathrm{min}^{-1}$; drug variable is Indo, assigned a value of -1 for preindomethacin conditions and +1 for postindomethacin conditions; interaction variable SW*I is the product of SW and the drug variable (it represents the interaction of indomethacin on the relation between MFV and SW); and lamb variables L1 through L8 represent the nine lambs. 


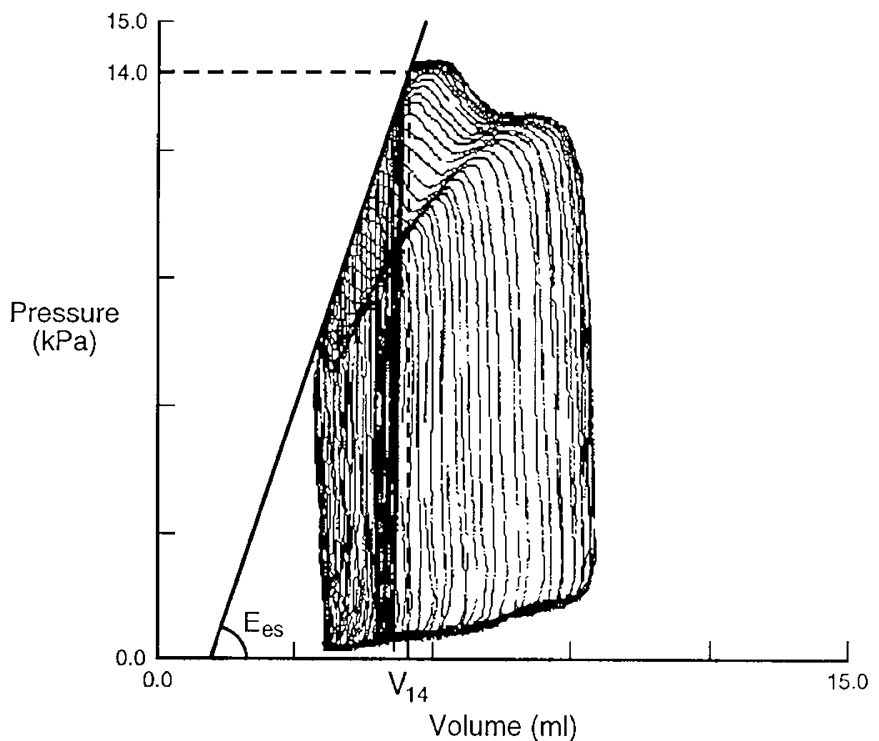

Fig. 3. Pressure-volume loops during a representative IVC occlusion when plotted on an $X-Y$ scale, with $E_{e s}$ and $V_{14}$.

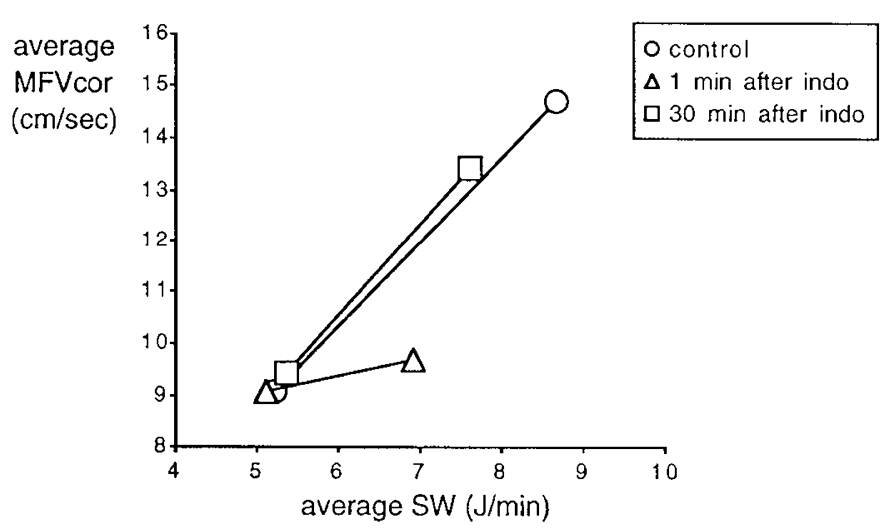

Fig. 4. Average MFVcor of the left circumflex coronary artery of all nine animals plotted against the average SW of all nine animals for three conditions: control $(O), 1 \mathrm{~min}(\triangle)$, and $30 \mathrm{~min}(\square)$ after indomethacin (indo).

work secondary to an increase in arterial pressure) with changes in flow that were due also to coronary vasomotor effects caused by the drug. Our results showed no change in the response of coronary flow to stepwise changes in cardiac demand 30 and 60 min after indomethacin administration in comparison with control. In the studies of Hintze and Kaley (21) and Dai and Bache (22), measurements were made also 30 and $60 \mathrm{~min}$, respectively, after indomethacin administration. However, our measurements immediately after indomethacin showed a significant increase in Rcor, which returned to the baseline value within 30 min without change in coronary flow. During this same period, SW was markedly increased, which is normally (without indomethacin) accompanied by a decrease of vascular resistance and an increase in coronary flow to adjust to the increased demand of the heart (Fig. 4). In other words, there is a distinct vasoconstrictive effect, appearing not as a decrease in flow but as a lack of expected increase in response to increased demand. This effect could be interpreted as a limitation of the coronary flow reserve caused by indomethacin, but the possibility of increased energy utilization, unlikely as it is, cannot be excluded (see below).

Although it might be possible that prostaglandins do play a role in the regulation of coronary blood flow, it seems unlikely that the acute effects of indomethacin are related to the blockade of prostaglandin production, inasmuch as these effects take place seconds after the administration. Chemtob et al. (23) showed in a recent study of awake piglets that, with a dose of $3 \mathrm{mg} / \mathrm{kg}$ indomethacin, there was no change in blood prostaglandin concentration at $20 \mathrm{~min}$ and a slight, nonsignificant decrease at 60 min. A dose of $10 \mathrm{mg} / \mathrm{kg}$ decreased the prostaglandin levels significantly, but the hemodynamic effects of these two doses were the same. This supports the hypothesis that acute vascular effects of indomethacin are not related to the blocking of the prostaglandin synthesis. Other possible explanations for these effects might be the inhibition of histamine release (24), its role as an oxygen radical scavenger (25), or, most likely, a direct effect of indomethacin on the vascular smooth muscle or endothelium.

Because a major decrease in coronary flow may impair ventricular performance, we measured this parameter before and after indomethacin infusion. We measured ventricular performance by the ESPVR at control and 30 and 60 min after indomethacin infusion: at these times coronary flow was normal, and there was no change in ventricular performance. Because there was no adequate steady state within the first 20 to $30 \mathrm{~min}$, we had to assess ventricular performance during and immediately after indomethacin infusion by a different technique. This was of special importance, inasmuch as the most prominent effects of indomethacin took place in this immediate period after administration. Information about the contractile state of the heart during this period is important, because a decrease in contractility may explain the increase in SW and yet increased coronary resistance, as shown in Figure 4. This reasoning is based on the linear relationship between myocardial oxygen demand and the pressure-volume-area concept (26). This relationship moves to a lower myocardial oxygen demand intercept when $E_{\text {es }}$ decreases (26). To determine this possibility, we estimated contractility by calculating $\mathrm{dP} / \mathrm{dt}_{\max }$ and corrected this value by relating it to changes in preload (end-diastolic volume). Using this index of contractility, we were not able to show a significant difference between the control and the acute situation. On the basis of this approximation of contractility, we can conclude that indomethacin does not change myocardial performance in the acute phase. The only other explanation for the apparent mismatch in output (SW) and input (coronary flow) is an increased oxygen extraction from the myocardial blood. This is very unusual, because under most circumstances the oxygen extraction reserve is not tapped, but rather blood flow increases to meet increased demand. However, the myocardium has the ability to extract more oxygen under certain circumstances, such a severe hypoxemia (27). We hypothesize that the use of indomethacin might also be such a circumstance. It is possible that indomethacin acutely constricts the coronary vessels and prevents these vessels from dilating fully in response to increased demand. Under those circumstances, it seems reasonable to argue that extraction will go up. This is supported by experimental studies in which an indomethacininduced decrease in organ blood flow was accompanied by a compensatory enhancement of oxygen extraction to maintain metabolic demands (28). Unfortunately, we were not able to measure the oxygen content values at these moments. Oxygen extraction and coronary venous lactate levels were not significantly different between the control period and 30 and $60 \mathrm{~min}$ after indomethacin infusion, when coronary flow and contractility were normal.

Finally, we have to address some potential problems with our techniques. We used the conductance catheter technique to estimate on-line LV volume, as has been described extensively for the adult "large" heart $(7,9,10)$. Recently, the feasibility, reliability, reproducibility (11), and accuracy (12) of this technique to determine ventricular performance in small hearts, using the ESPVR, have also been demonstrated. The conductance catheter technique is subjected to two errors, parallel conductance caused by tissue surrounding the LV cavity and a species-specific constant, $\alpha$, which relates actual SV to measured SV (29). We corrected for parallel conductance by calculating its value with the salt injection technique described earlier in this 
article. As $\alpha$ is species-specific, we did not correct for this value, but because it can range from 0.5 to 0.9 (29) it will cause SV and therefore $\mathrm{CO}$ values to be rather low. The values of the $\mathrm{CO}$ we measured were indeed low compared with other studies. Besides the $\alpha$ effect, another reason for the low $\mathrm{CO}$ values is that we studied anesthetized animals, in which CO is known to be considerably lower. With respect the ESPVR, its afterload sensitivity must be taken into account $(9,10)$; we carefully performed our interventions in such a way that this was possible. In this particular study, the afterload effect was of less importance, because the intervention to change loading conditions was the same for the different conditions during which we measured LV systolic performance.

Lastly, there has been considerable disagreement about the appropriate dose and speed of indomethacin in the clinical setting. It seems unlikely, though, that our results are influenced by the dose of indomethacin. The dose we used is about three times the dose used in neonatal infants, but sensitivity for indomethacin varies considerably among species. In fact, most studies in newborn lambs have been performed with much higher dosages than those used in our study. Moreover, experimental and clinical studies have shown that the effects of indomethacin on organ perfusion are relatively dose-independent $(23,30,31)$. We administered indomethacin over a period of about $60 \mathrm{~s}$, because this is the usual procedure in clinical practice.

We conclude that, although no negative effects on myocardial perfusion and performance were found after indomethacin infusion, the transient coronary vasoconstriction that occurs during and shortly after administration should alert the clinician to its potential risks in those infants in whom a preexisting limitation in coronary flow reserve is suspected. Additional investigation is needed to fully understand the vasomotor actions of indomethacin and the alterations in these effects by variations in dosing regimens.

\section{REFERENCES}

1. Bel van F, Bor van de M, Stijnen T, Baan J, Ruys JH 1988 Cerebral blood flow velocity changes in preterm infants after a single dose of indomethacin: duration of its effect. Pediatrics 84:802-807

2. Bel van F, Guit GL, Schipper J, Bor van de M, Baan J 1991 Indomethacininduced changes in renal blood flow velocity waveform in premature infants investigated with color Doppler imaging. J Pediatr 118:621-626

3. Bel van F, Zoeren van D, Schipper J, Guit GL, Baan J 1990 Effects of indomethacin on superior mesenteric artery blood flow velocity in preterm infants. J Pediatr 116:965-970

4. Friedman PL, Brown EJ, Gunther S, Wayne Alexander R, Barry WH, Mudge GH, Grossman W 1981 Coronary vasoconstrictor effect of indomethacin in patients with coronary artery disease. N Engl J Med 305:1171-1175

5. Pacold I, Hwang MH, Lawless CE, Diamond P, Scanlon PJ, Loeb HS 1986 Effects of indomethacin on coronary hemodynamics, myocardial metabolism and anginal threshold in coronary artery disease. Am J Cardiol 57:912915

6. Appleton RS, Graham TP, Cotton RB, Moreau GA, Boucek Jr RJ 1988 Decreased early diastolic function after indomethacin administration in premature infants. J Pediatr 112:447-451
7. Baan J, Van Der Velde ET, De Bruin HG, Smeenk GJ, Koopo J, Van Dijk AD, Temmerman D, Senden PJ, Buis B 1984 Continuous measurement of left ventricular volume in animals and humans by conductance catheter. Circulation 70:812-823

8. Kass DA, Yamazaki T, Burkhoff D, Maughan WL, Sagawa K 1986 Determination of the left ventricular end-systolic pressure-volume relationship by the conductance (volume) catheter technique. Circulation 73:586-595

9. Baan J, Van Der Velde E 1988 Sensitivity of left ventricular end-systolic pressure-volume relation to type of loading intervention in dogs. Circ Res $62: 1247-1258$

10. Van Der Velde E, Burkhoff D, Steendijk P, Karsdon J, Sagawa K, Baan J 1991 Nonlinearity and load sensitivity of end-systolic pressure-volume relation of canine left ventricle in vivo. Circulation 83:315-327

11. Teitel DF, Klautz RJM, Steendijk P, Van Der Velde ET, Van Bel F, Baan J 1991 The end-systolic pressure-volume relationship in the newborn lamb: effects of loading and inotropic interventions. Pediatr Res 29:473-482

12. Cassidy SC, Teitel DF 1992 The conductance volume catheter technique for measurement of left ventricular volume in young piglets. Pediatr Res 31:85 90

13. Suga H, Sagawa K 1974 Instantaneous pressure-volume relationships and their ratio in the excised, supported canine left ventricle. Circ Res 35:117-126

14. Sagawa K 1978 The ventricular pressure-volume diagram revisited. Circ Res 43:677-687

15. Little WC 1985 The left ventricular $\mathrm{dP} / \mathrm{dtmax}$-end-diastolic volume relation in closed-chest dogs. Circ Res 56:808-815

16. Glantz SA, Slinker BK 1990 Primer of applied regression and analysis of variance. McGraw-Hill, New York

17. Greenberg J, Noordergraaf A, Reivich M 1978 Control of cerebral blood flow: models and experiments. In: Baan J, Noordergraaf A, Raines $\mathbf{J}$ (eds) Cardiovascular System Dynamics. MIT Press, Cambridge, MA pp 391-398

18. Vane JR 197I Inhibition of prostaglandin synthesis as a mechanism of action for aspirin-like drugs. Nature [New Biol] 231:232-235

19. Afonso S, Bandow GT, Rowe GG 1974 Indomethacin and the prostaglandin hypothesis of coronary blood flow regulation. J Physiol 241:299-308

20. Needleman P 1976 The synthesis and function of prostaglandines in the heart. Fed Proc 35:2376-2381

21. Hintze TH, Kaley G 1977 Prostaglandin and the control of blood flow in the canine myocardium. Circ Res 40:313-320

22. Dai XZ, Bache RJ 1984 Effect of indomethacin on coronary blood flow during graded treadmill exercise in the dog. Am J Physiol 247:H452-H458

23. Chemtob S, Beharry K, Barna T, Varma DR, Aranda JV 1991 Differences in the effects in the newborn piglet of various nonsteroidal antiinflammatory drugs on cerebral blood flow but not on cerebrovascular prostaglandin. Pediatr Res 30:106-111

24. König W, Brom J, Schönfeld W, Knöller J, Stüning M 1987 Effect of tenoxicam and indomethacin on the release of histamine, prostaglandin $E_{2}$ and leukotrienes from various cells. Arzneimittelforschung 37:296-299

25. Ment LR, Stewart WB, Duncan CC 1985 Beagle puppy model of intraventricular hemorrhage: effect of superoxide dismutase on cerebral blood flow and prostaglandins. J Neurosurg 62:563-569

26. Suga $H$ Yasumura $Y$, Nozawa $T$, Futaki S, Tanaka N, Uenishi M 1988 Ventricular systolic pressure-volume area (PVA) and contractile state (Emax) determine myocardial oxygen demand. Adv Exp Med Biol 222:421-430

27. Bernstein D, Teitel DF 1990 Myocardial and systemic oxygenation during severe hypoxemia in ventilated lambs. Am J Physiol 258:H1856-H1864

28. Leffler C, Busija D, Beasley D 1987 Effect of therapeutic dose of indomethacin on the cerebral circulation of newborn pigs. Pediatr Res 21:188-192

29. Baan J, Van Der Velde ET, Steendijk P, Koops J 1989 Calibration and application of the conductance catheter for ventricular volume measurement. Automedica 11:357-365

30. Naden RP, lliya CA, Arant BS, Gant NF, Rosenfeld CR 1985 Hemodynamic effects of indomethacin in chronically instrumented pregnant sheep. Am J Obstet Gynecol 151:484-493

31. Cowan F 1986 Indomethacin, patent ductus arteriosus and cerebral blood flow. J Pediatr 109:341-344 